\title{
O viajante e o pesquisador
}

\section{The traveler and the researcher}

Paulo Henrique Torres Valgas ${ }^{1}$ 
Resumo

Este artigo trata da trajetória da pesquisa acadêmica sendo abordada como uma metáfora da viagem e do viajante. Enquanto realiza-se uma análise da tese da professora Sandra Makowiecky e da sua própria pesquisa, pensa-se também nos relatos de Marguerite Duras e outros pesquisadores cujos textos encontramse no livro "A bússola do escrever". Os mesmos artistas selecionados para a tese de Makowiecky são tratados aqui como referências às próprias experiências de construção de uma tese/dissertação.

Palavras-chave: viagem, viajante, cidade, pesquisa, tese.

\section{Abstract}

This paper is about the academical trajetory being discussed as a metaphore of the traveling and of the traveler. While is done an analysis of Sandra Makowiecky's thesis and of his own research, the author thinks about the experience of Marguerite Duras and other researchers, which texts are found in the book "The compass of writing". The same artists selected by Sandra in her thesis are discussed here as references of the own experiences of building of a thesis/ dissertation.

Keywords: travel, traveler, city, research, thesis.

ISSN: 2175-2346

${ }^{1}$ Graduado em História especialista em História da Arte, ambos pela Unisul. Cursa mestrado em Artes Visuais, orientação de Sandra Makowiecky e é professor do Instituto Federal Catarinense. Brasil. paulotorres 1989@hotmail.com 
Escrever uma tese ou uma dissertação é um processo repleto de encantos, surpresas, desastres, desgostos, angústias, prazeres. Tudo isso ao mesmo tempo, borbulhando dentro do pesquisador. $O$ desejo por mais conhecimento, o cansaço da leitura, os prazos que batem à porta, os periféricos que nos chamam atenção (para o "bem" ou para o "mal"), o relógio que parece magicamente acelerar: tudo isso faz parte da vida do "fazedor de tese". Por isso, ser apaixonado pela sua pesquisa é o primeiro requisito. Do contrário, o sucesso do trabalho está certamente comprometido. Esse artigo trata de uma análise da tese de doutorado da professora dra. Sandra Makowiecky, da minha própria pesquisa e dos escritos de pesquisadores sobre suas práticas, como textos de Alda Judith Alves-Mazzotti no livro "A bússola de escrever", onde com um tom cômico e muita espirituosidade, cita alguns erros comuns numa tese e cria nomes caricatos para eles. Ambos estão relacionados de uma forma diferente: comparando a trajetória da pesquisa com a prática de um viajante, tais como esses que conhecemos das telas pintadas no barroco e no romantismo.

"Castelo de Hadleigh", de John Constable (imagem 1), mostra um viajante ao lado de seu cão, figura mais emblemática da amizade. Ele carrega uma mochila, onde guarda seus pertences, tudo que já adquiriu até então. O castelo em ruínas é o problema de pesquisa: as rachaduras, os incômodos, os questionamentos, aquilo que nos faz sentir vontade de ir além e descobrir mais. Logo após ele, um declive. Pesquisar é isso: assumir que ainda não sabe o bastante, tornar-se discípulo, aprendedor, enfrentar novas leituras e abordagens que podem nos fazer escorregar tal como na grama molhada onde os gados pastam. Afinal, encarar um mestrado ou doutorado é um projeto que "mobiliza todas as forças do sujeito, pois trata-se de uma tarefa antissocial e excludente, desestabilizadora de certezas intelectuais, comportamentais e emocionais" (FREITAS, 2006, p. 216). As nuvens da tela são ora claras, ora escuras. Passamos, no decorrer da construção da dissertação ou tese, momentos tais como estes. Momentos de claridade, de "iluminação", de insights que podem transformar os rumos da pesquisa - para melhor, mas também momentos obscuros, travados, ansiosos pela nuvem carregada que anuncia temporal. Raios, trovões, ventania: talvez esse é o momento em que os problemas do dia a dia vêm e nos obriga a, mesmo escondidos debaixo do sofá, com travesseiros a tapar os ouvidos, a escrever, escrever, escrever. 


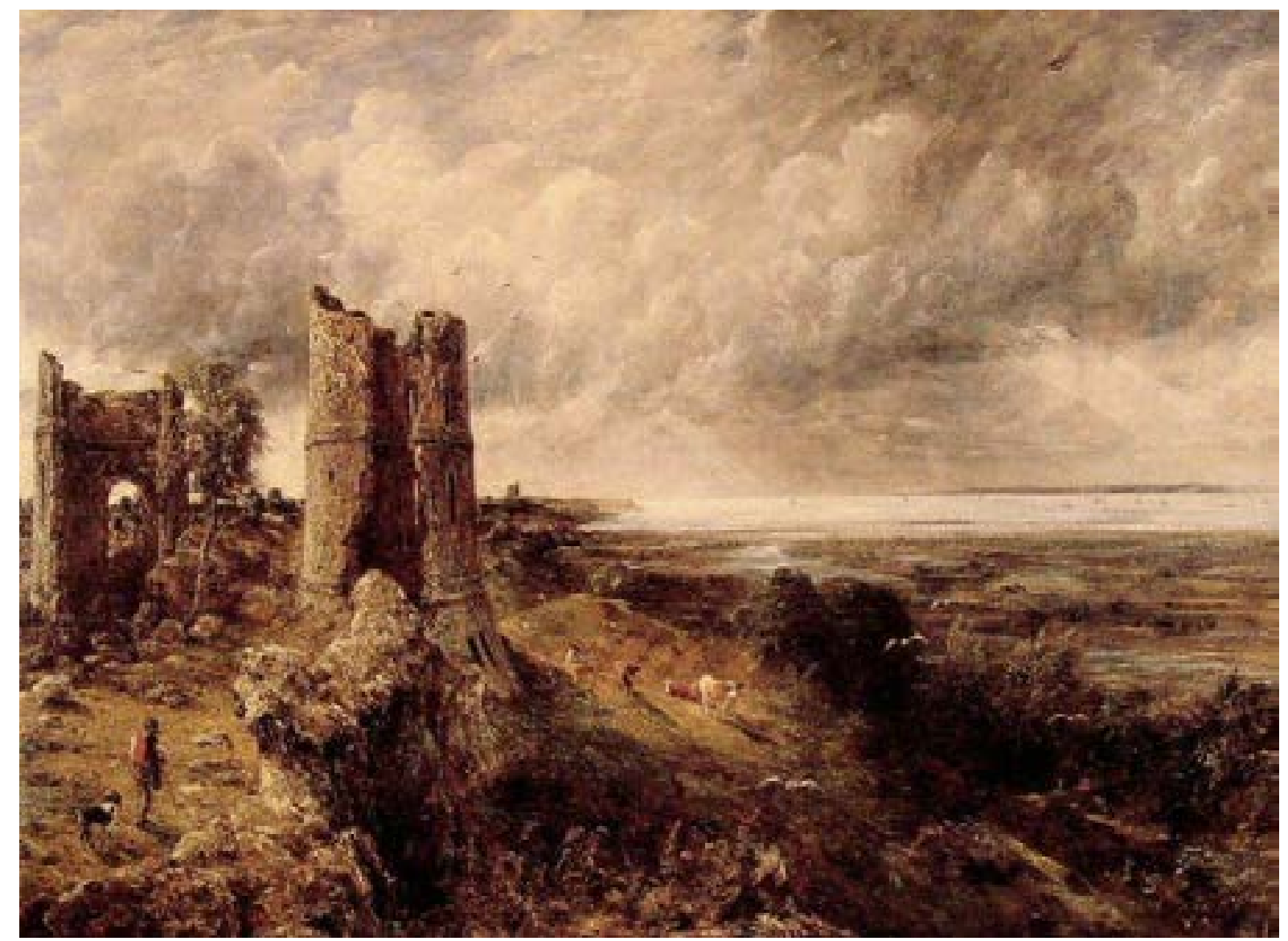

Imagem 1: John Constable. Castelo de Hadleigh. 1829. Óleo sobre tela. Yale center for British art. New Haven, Estados Unidos.

Essa tela é belíssima pela sua ruína, pela sua melancolia, pelo seu potencial sensitivo. Novamente comparável à escrita e à pesquisa. Nem tudo é bonito só por ser verde e ensolarado. Há beleza também na privação (quantas!), na solitude, no caminho tortuoso. E mesmo em meio à nuvens negras, fechos de luz solar nos guiam no caminho, caminho esse que será aplainado por quem um dia receberá o mérito por tal feito, por onde outros passarão facilmente para então abrir novas passagens. Alves-Mazzotti afirma que "a produção do conhecimento não é um empreendimento isolado", mas "uma construção coletiva da comunidade científica, um processo continuado de busca, no qual cada nova investigação se insere, complementando ou contestando contribuições anteriormente dadas ao estudo do tema." (2006, p. 27). Por isso, há muitos viajantes solitários cuja solitude é aparente. Só não nos enxergamos, talvez não nos encontramos ainda.

No ano de 2003 a tese da professora doutora Sandra Makowiecky foi defendida no Programa Interdisciplinar de Ciências Humanas na Universidade Federal de Santa Catarina - UFSC. O título do seu trabalho é "A representação da cidade de Florianópolis na visão dos artistas plásticos", pesquisa que está repleta de uma paixão da pesquisadora, nascida na cidade e orgulhosa de sua aldeia, que assumiu a tarefa de viajar pela história da sua terra. Esse título não deixa segredos quanto ao tema, embora seja extremamente abrangente. O recorte, se é possível dizer assim, engloba os primeiros artistas viajantes europeus, entusiasmados com o novo mundo, desde o século XVI até o século XIX, quando também desponta Victor Meirelles, primeiro a fazer da ci- 
dade de Florianópolis tema para uma obra de arte. A pesquisa continua com o século $\mathrm{XX}$, agrupado por décadas, configurando assim a parte final de seus capítulos. Seu recorte encerra na década de 90, visto que a pesquisa encerrou-se em 2002.

O objeto se constitui, então, da forma como a cidade foi representada por artistas que por aqui passaram e viveram, cada um na sua particularidade. As perguntas que desdobram-se nas suas hipóteses estão pautadas no interesse em descobrir se essas representações disponibilizam ferramentas para analisar fenômeno urbano da capital catarinense. Além disso, Sandra busca desmistificar o esteriótipo da cidade como llha da Magia, criada devido à intensa colonização açoriana local. Ela defende que, como todo esteriótipo, esse não corresponde à identidade florianopolitana em sua totalidade. A terceira hipótese é a de que a cultura da modernidade é eminentemente urbana e a quarta está vinculada ao referencial teórico utilizado.

A configuração do trabalho é muito prática e clara. Sua introdução descreve todos os passos e métodos do trabalho. Nela, o objeto e o problema são identificados. Sandra deixa claro que toda imagem é polissêmica e que cada trabalho é regido por um regime de verdades que se coloca como norte para aquele determinado olhar, mas que é totalmente mutável, ou seja, há uma abrangência muito grande de possibilidades. Ainda na introdução são explicitados seus objetivos: a avaliação das possibilidades do uso da imagem como elemento de compreensão das imagens de Florianópolis ao longo do tempo, identificar esteriótipos, realizar uma pesquisa academicamente qualificada, intercalar História, História da Arte, Sociologia e Psicologia e preencher uma lacuna na história da arte catarinense $(2012$, p. 33). Ainda na introdução, ela destaca o valor e a importância de sua pesquisa, afirmando que esta servirá para novos trabalhos em História da Arte, Planejamento Urbano, História e Psicologia (idem, p. 35), o que configura sua pesquisa como um tipo de glossário da representação artística florianopolitana. Ela prossegue descrevendo a metodologia, que consiste em analisar imagens, textos críticos ou autobiográficos, entrevistas e o circuito de arte.

$\mathrm{Na}$ implementação de um referencial teórico, Sandra opta por utilizar-se da teoria representativa de Ernst Gombrich, embasada no livro "Meditações sobre um cavalinho de pau"; e da teoria de Christine Boyer sobre a representação das cidades, classificada pela autora como obra de arte, panorama ou espetáculo. Leitora dos diversos teóricos de arte, Sandra não se utiliza de muitos, pois entende que o objeto determina a teoria e não o contrário. Isso faz com que ela não cometa erros como o que Alves-Mazzotti chama de erro do "cronista social", ou seja, aquele autor que cita o teórico que está "na moda" ou o teórico "curinga", aquele que vale para justificar qualquer ideia. (2006, p. 37). Outro erro comum que Sandra toma cuidado para não cometer é misturar e fazer o que Alves-Mazzotti chama de "coquetel teórico" (idem, p. 38), chamado pela professora dra. Rosângela Cherem de um tipo de "jantar com inimigos", quando defende que se façam combinações coerentes ou então que se use bons argumentos para "levar à mesa" teóricos contraditórios.

O primeiro capítulo da tese de Sandra trata de uma revisão bibliográfica, parte da tese classificado por Alves-Mazzotti (idem, p. 27), em dois tipos: aquela que é básica para a realização do trabalho e de necessidade prévia para o autor; e aquela que vai de fato integrar o relatório do estudo. Saber diferenciar isso é essencial, torna a 
pesquisa mais sólida, menos cansativa e com especificidade. Sandra toma cuidado para não cair nas ciladas metodológicas comuns, como a tentativa falsa de esgotar um assunto ou então traçar um cansativo contexto histórico que depois torna-se inútil, chamados por Alves-Mazzotti de revisão bibliográfica tipo summa e arqueológica (idem, p. 34). Sandra admite que o tema é abrangente e sua pesquisa passa por escolhas metodológicas e teóricas necessárias. Afirma também, inclusive no título do capítulo II, que é necessário não somente conhecer as definições, mas as imprecisões necessárias. Em sua revisão bibliográfica ela não delonga-se sobre a história da cidade ou de sua representação, citando o essencial, como por exemplo, que a primeira cidade pintada e tratada como tema na história foi feita por Ambrogio Lorenzetti durante o Renascimento (2012, p. 58). Os tipos "suspense" e "rococó" (2005, p. 35) de Alves-Mazzotti também são evitados por Sandra, que na introdução é tão clara quanto ao que se seguirá que as surpresas do trabalho são produtos da pesquisa e não da falta de informação prévia. A linguagem é acadêmica, porém acessível, sem palavras difíceis, sentidos duplos ou enfeites verbais da moda e/ou sem significado: cada palavra significa algo muito concreto e embora abrangente, a junção delas formula o verdadeiro objetivo da tese, ou seja, não se rende aos excessos, como no estilo rococó.

Sandra Makowiecky orienta minha pesquisa de mestrado, que compartilha da mesma paixão e objeto: a cidade. Minha viagem, porém, não é temporal, mas espacial. Trata-se de uma pesquisa sobre o grupo de desenhistas urbanos Urban Sketchers, fundado pelo espanhol Gabriel Campanário em 2008 e trazido ao Brasil em 2011. O grupo reúne pessoas interessadas em desenhar e pintar as cidades onde vivem ou para onde viajam, não importando a técnica que utilizem e apoiando-se mutuamente. A finalidade do grupo e de sua prática é "mostrar o mundo, um desenho de cada vez." O grupo não se insere no circuito de arte convencional, expondo principalmente nas redes sociais e sendo formado majoritariamente por desenhistas sem status artístico. Seu blog nacional tem mais de trinta correspondentes, enquanto que no perfil do Facebook mais de 5000 pessoas compartilham seus desenhos. O ponto chave e fio condutor para a pesquisa será o manifesto que eles têm como norte para sua produção. Sandra ajudou-me a perceber o quão deslocado está o grupo: fora do museu, fora do circuito, fora do seu tempo (no sentido de o que, como e porque produz), além de conduzir-se por um manifesto, uma prática das vanguardas europeias do início do século XX. Esse fato da história da construção da minha dissertação me lembra o capítulo III da tese de Sandra, intitulado "A metáfora da viagem e o olhar estrangeiro", que explica o relato de Montaigne sobre um índio que foi levado à Europa e questionou porque os pobres de lá não matavam seus opressores e incendiavam suas casas $(2012$, p. 84). Se pautando nessa história, ela mostra como o olhar de fora é importante. Trazendo para meu caso, como é importante a presença do orientador para nos podar, incentivar, olhar de fora e dar uma posição consistente, e acima de tudo, fazer-nos descobrir o que está diante de nossos olhos, ainda obscuro. Quem já trilhou os caminhos da pesquisa, conhece-os ou os vê de fora, pode dar conselhos muito úteis neste momento. 


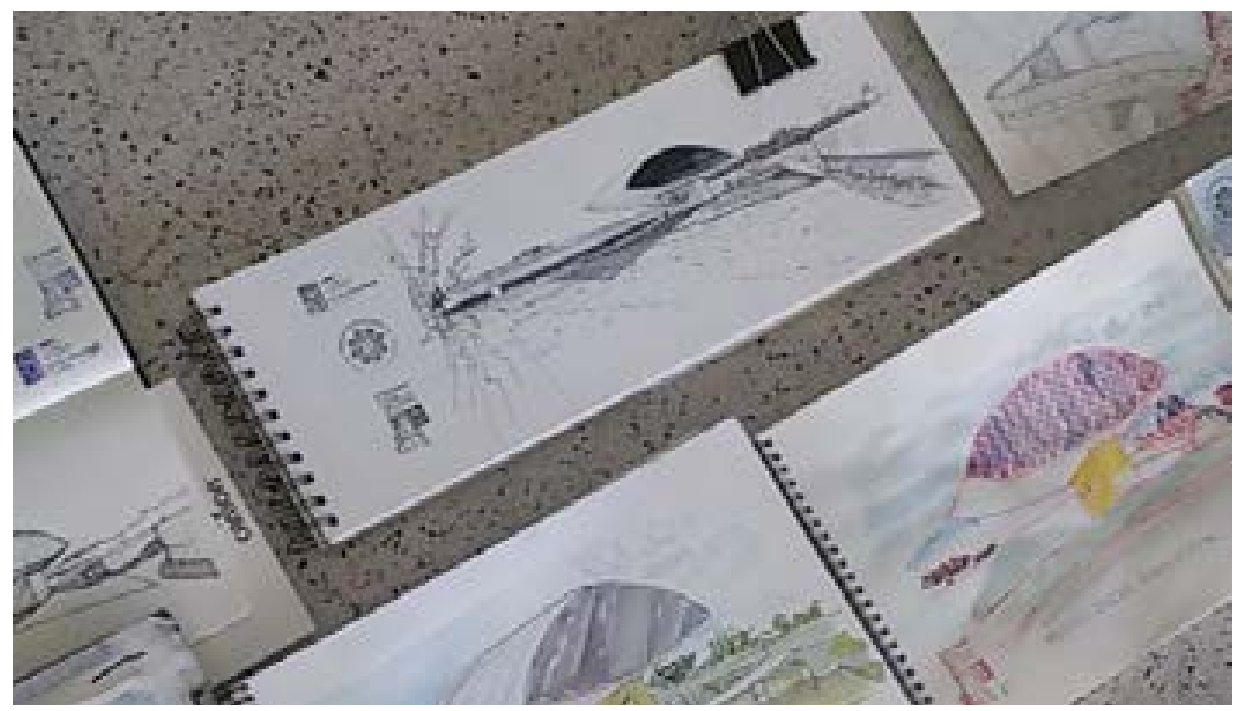

Imagem 2: Exposição de trabalhos no I Encontro Nacional de Urban Sketchers. Curitiba, 2016.

A proposta de nossos trabalhos é fenomenológica, ou seja, tem a realidade como o compreendido, o interpretado, o comunicado, e nunca é única. Sandra trata sua tese como arqueologia poética, buscando facilitar o caminho para encontrar nossos "deuses", ideia baseada em Ítalo Calvino, cujos elementos comuns que distinguem uma cidade da outra, a alma da cidade, podem e devem ser interrogados e descobertos. É impossível e desonesto desvincular nossos amores de nossa pesquisa. Os urban sketchers, por exemplo, são mais que desenhistas panorâmicos da realidade: são cronistas, utilizam-se de sua técnica, mas sobretudo de sua experiência, da sua compreensão de mundo, de suas preferências. Relatam o que seus olhos, mas também sua singularidade vê. Na imagem 2, vê-se a exposição de desenhos e aquarelas retratando o Museu Oscar Niemeyer de Curitiba no Encontro Nacional do grupo em abril de 2016. O mesmo local, desenhado por quase trezentas pessoas, rendeu o mesmo número de singularidades.

Relacionar as temáticas da tese de Sandra com minha temática seria enfadonho para o momento em que minha pesquisa ainda está em andamento, por isso prefiro relacionar as minhas vivências e percepções durante o andamento da pesquisa com a figura do viajante e da viagem retratada na pesquisa de Sandra. Seu capítulo V inicia com os artistas viajantes. Viajar de uma cidade para outra, representá-la, gravá-la na retina, conhecer o novo, o inusitado. Viajar tem sido uma palavra-chave do meu mestrado, pois não moro em Florianópolis. Meu primeiro semestre me custou trezentos quilômetros e quatro horas por semana; meu segundo semestre, quinhentos e cinquenta quilômetros e sete horas, isso porque eu mudei de cidade. Por isso, a estrada, a velocidade, o olhar assustado para o novo me fazem sentir-me um itinerante, um homem que tem duas ou três camas e quartos, que tem no carro uma segunda casa. Meus objetos estão espalhados pela minha cidade original, pela minha cidade atual e pela cidade onde estudo. Todo o esforço, porém, vale a pena. É possível pintar belos quadros em minha mente, frutos dessa experiência.

Como em uma das mais famosas pinturas de Victor Meirelles, Vista do Desterro, de 1847 (imagem 3), vejo o percorrer do mestrado como essa rua que traça o meio 
do quadro e leva ao horizonte. Essa área aberta no primeiro plano é como o trampolim para iniciar a pesquisa acadêmica. Dali, você tem uma rua a seguir, reta, pois sabe que embora cada um tenha sua singularidade, o caminho é um só aos seus sonhos: dedicação e persistência. No horizonte, ao fundo, vê-se o mar e as montanhas. De lá, cada um tomará seu rumo, nadando e trilhando caminhos diferentes. Assim como na tela, no mestrado temos várias ruas paralelas nos convidando a entrar: um passeio, uma noite com amigos, o cônjuge ou as crianças que chamam por atenção. Nada disso é proibido. Mas a "cidade-mestrado" é como uma colônia portuguesa: não há planejamento e as ruas não tem retornos tão fáceis. É preciso cautela. Quando nos perdermos, temos como sinal a cruz no alto: nossos livros, nossa biblioteca, um puxão de orelha do orientador, uma nota baixa. Para quem olha de cima, da área aberta do primeiro plano, parece muito mais fácil ditar o caminho: óbvio! Elas não estão trilhando.

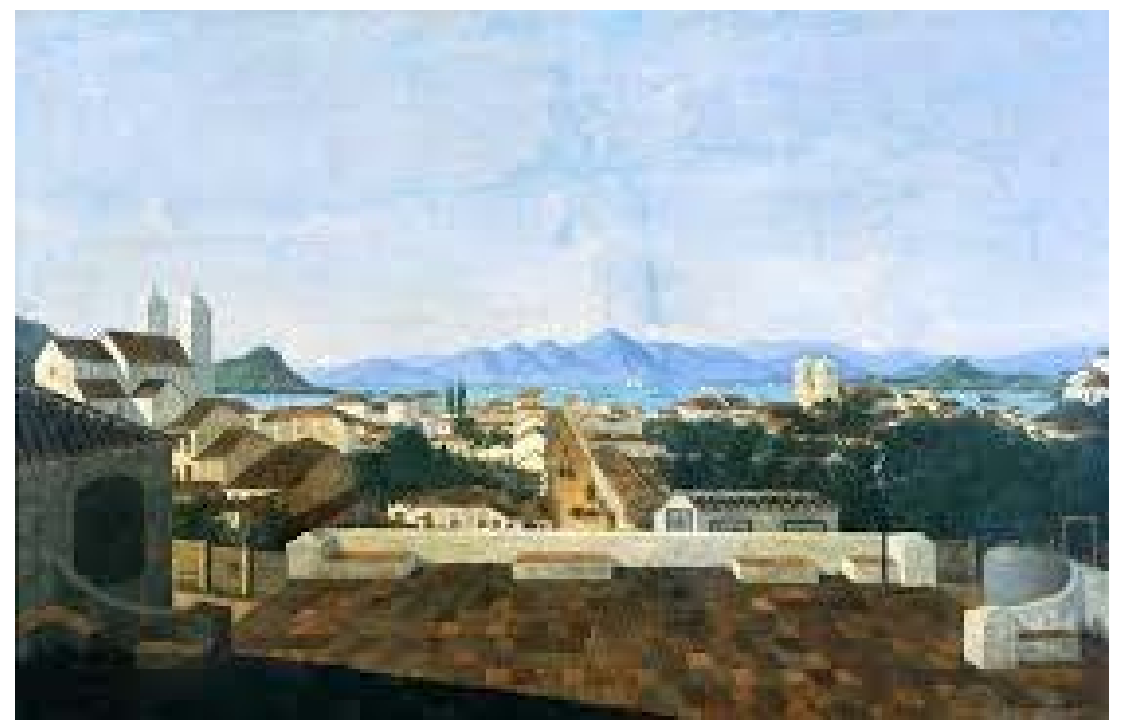

Imagem 3:Victor Meirelles. Vista do Desterro. 1847.

Óleo sobre tela. Museu Victor Meirelles.

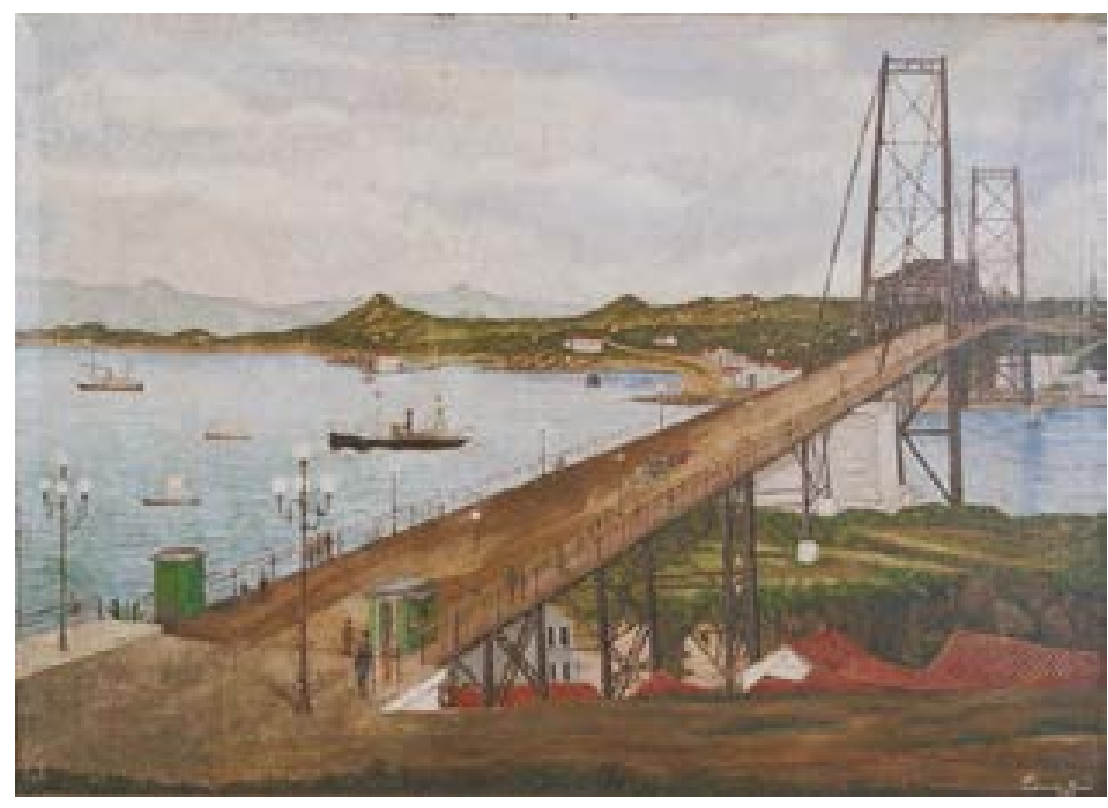

Imagem 4:Eduardo Dias. Ponte Hercílio Luz. 1930.

Óleo sobre tela. Museu de Arte de Santa Catarina. 
Na pintura de Eduardo Dias, Ponte Hercílio Luz, de 1930 (imagem 4), vejo minha vida durante o mestrado representada em um dos barquinhos. Dele, pode-se ver a ponte e a cidade, as pessoas vivendo normalmente: passeando, conversando, trabalhando; as luzes acesas para guiar os seus passos. Quanto ao barquinho, pode padecer numa tempestade, ou no escuro em busca de um farol. Não dá pra usar a âncora quando estiver em alto-mar. O leme pode quebrar. Podemos olhar para o barco ao lado, maior e mais equipado: seria o colega que já está tão à frente? As pessoas acenam para nós e se questionam porque não voltamos logo para terra firme. Elas não sabem o quanto é difícil alcançá-la durante a fase da construção. Mas ela é necessária. Assim como na tela de Martinho de Haro, Costa de Florianópolis (imagem 5), o barco que chega ao cais revela o que Fernando Pessoa chama de saudade de pedra. É o dia de ir visitar a família, de sair com os amigos, de ver um filme banal ou ler a revista de fofocas ou sobre o filme que entrará em cartaz ainda esse ano. É voltar às nossas origens, é descarregar o barco das novas descobertas e logo, seguir em frente outra vez. O orientador é o guia da carruagem que recolhe tudo e diz: "Traga mais!". Ou ainda: "Traga mais até o dia tal!".

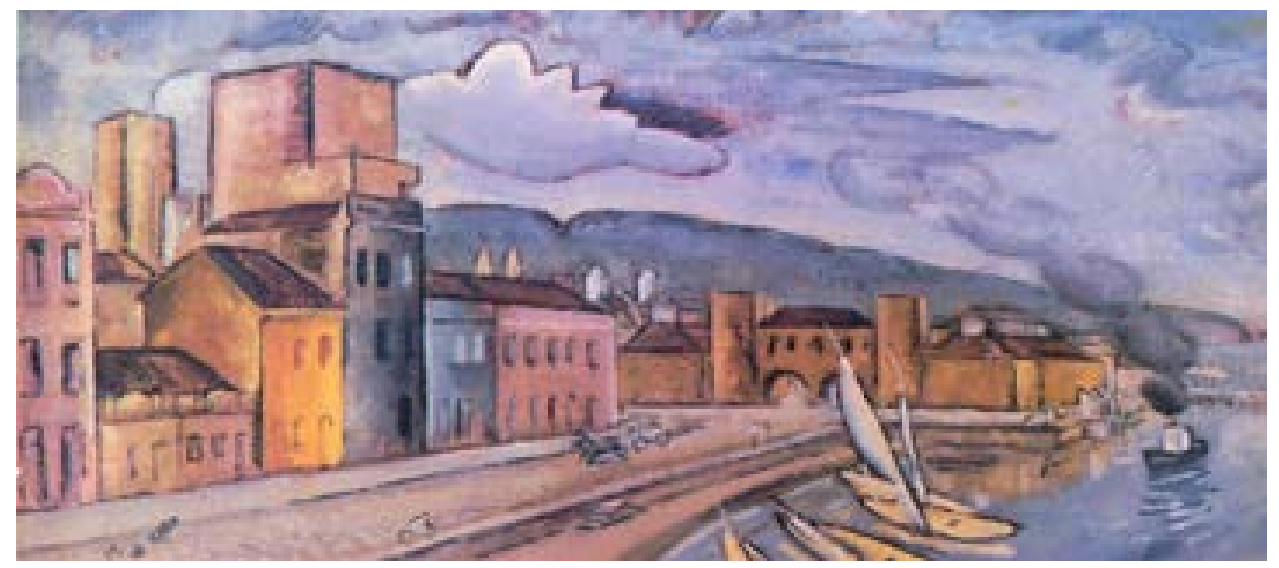

Imagem 5:Martinho de Haro. Costa de Florianópolis. Óleo sobre eucatex. Coleção Danton Vampré Junior.

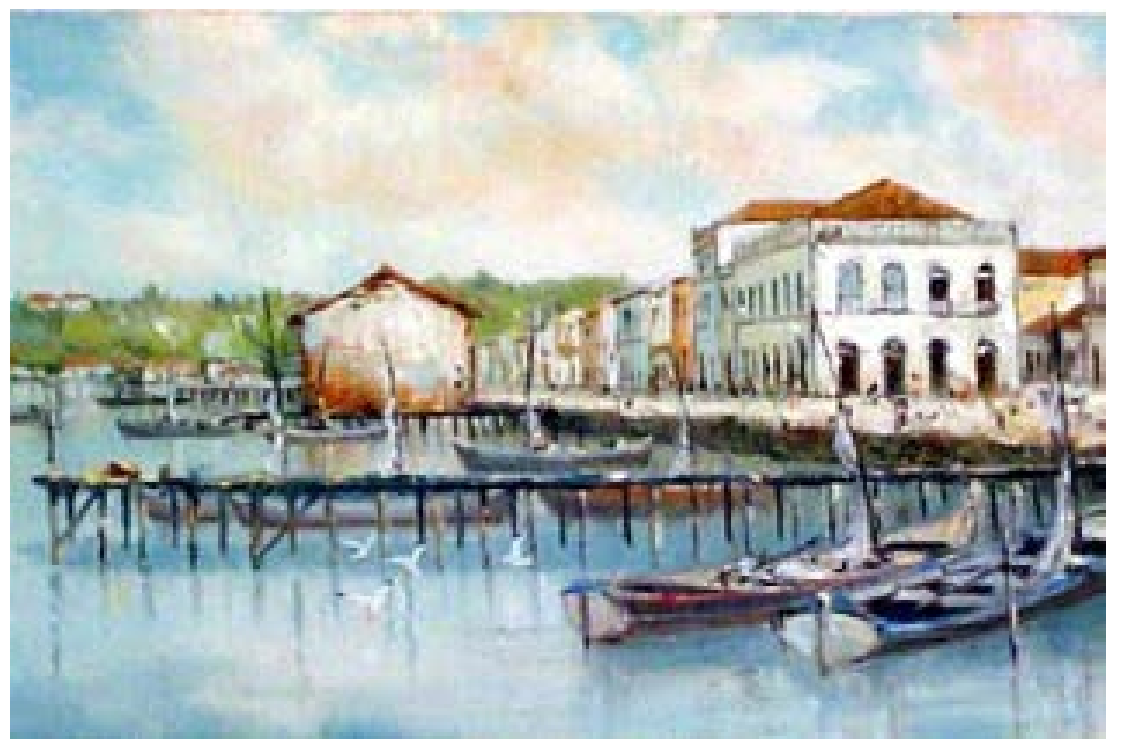

Imagem 6: Aldo Beck. Antiga Florianópolis. 1985. Óleo sobre tela. Acervo Artur Beck Neto. 
Há momentos, então, que já não sabemos o que queremos. Já não sabemos o que sabemos, tornamo-nos não-sabedores, termo que uso para descrever-me nas tantas horas que penso que minha dissertação vai ser uma tragédia. É a hora de chorar, como ensina Duras: "E não chorar nunca é não viver. Chorar, é preciso que isso também aconteça. Se chorar é inútil, mesmo assim creio que é preciso chorar." (1994, p. 46) É como nas telas de José Vieira D'Avila, meu mundo de eterna luta entre sombras e luz, anjos e demônios, bem e mal vêm à tona. São momentos de solidão, não aquela desejada para se poder produzir, mas aquela indesejada, a solidão acompanhada, onde ninguém parece entender o que você está fazendo. Essas pessoas, porém, só sabem que é algo muito importante e que exige muito, por isso te respeitam. Esses momentos, de carinho, ternura e respeito, admiração e espanto, são como a pincelada terna de Aldo Beck em "Antiga Florianópolis", tela de 1985 (imagem 6). Nela, ele retrata um dia em Florianópolis, com uma mistura de verde e azul que se encontram com a melancolia do porto e dos passantes da beira-mar. Me parece impossível não desejar estar ali, sentar-me a beira do cais, andar pelas ruas, molhar os pés na água. Nós, pesquisadores de arte, temos esse refúgio ainda mesmo em nossos objetos, o que nos coloca em vantagem e, as vezes, em perigo.

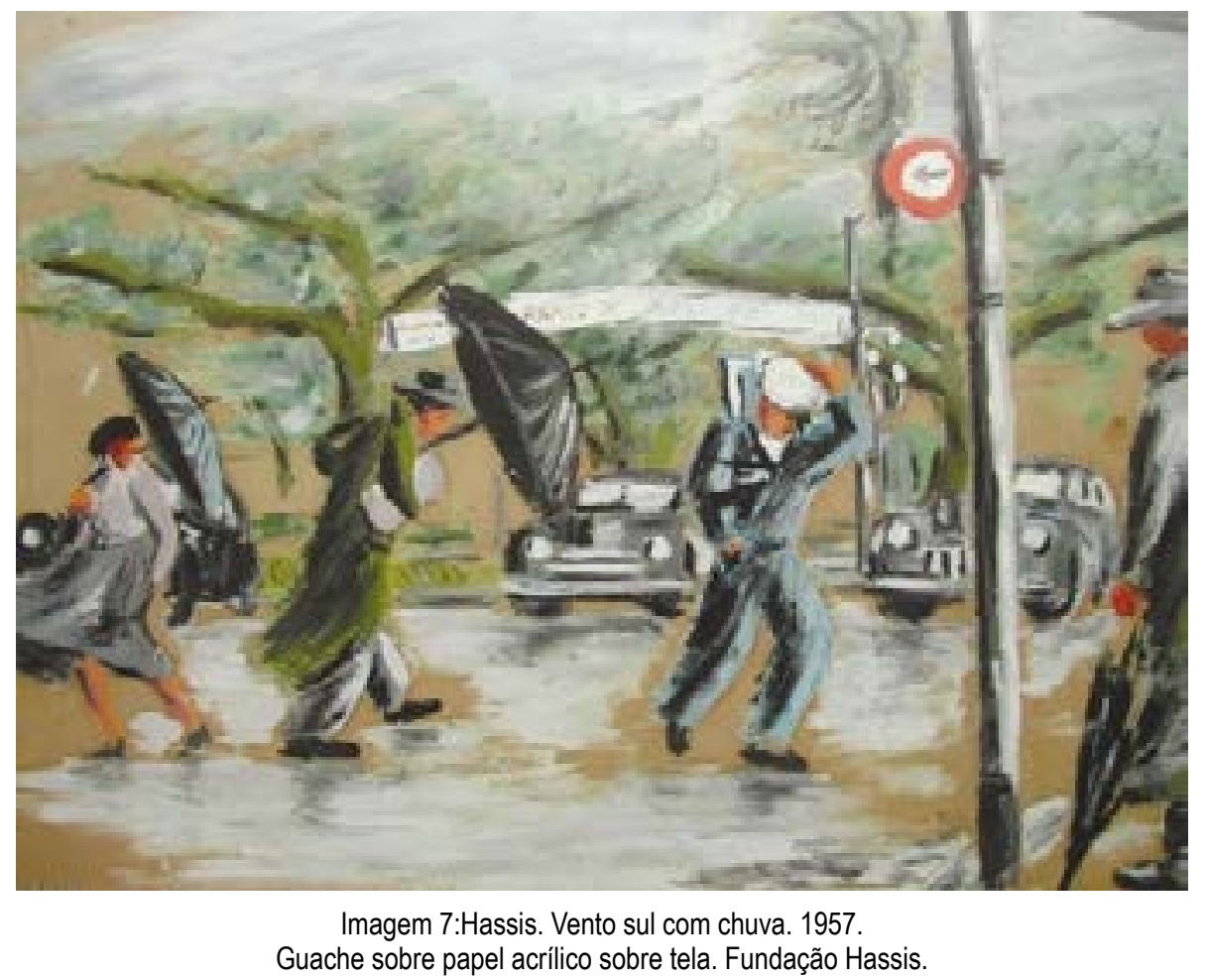

Uma imagem usada no capítulo X, sobre as décadas de 20 e 30, lembra-me que no olho do furacão se encontra o que se precisa. Na correria entre uma aula e outra, uma conversa, um desabafo com o colega ou com o orientador, na longa viagem até casa, na turbulência, pode-se ter um insight, um olhar que dê mais respostas do que mil palavras. Assim acontece na tela "Vento sul com chuva", de Hassis (imagem 7). 0 vento que assombra o litoral catarinense, trazendo chuva e bagunça, mau humor, precaução, horas de atraso, banhos em poças d'água, faz qualquer abrigo servir. Há, porém, uma linha horizontal imaginária que corta o quadro: um homem e uma mu- 
lher se entreolham. Mil interpretações suscitam, mas o que preciso saber por agora é que são esses olhares que precisamos vislumbrar enquanto fazemos uma tese ou dissertação.

Outro aspecto da pesquisa é o tempo. Vejo-o na tela de Fossari, "Teatro Álvaro de Carvalho no século XIX". O tempo em português tem apenas uma forma de expressão; em grego, três. Na obra de Fossari, consigo vê-los. O tempo cronológico, o tempo da chegada, é ansiado e temido. Ansiado o fim da tese, a defesa, o título e o certificado, os tapas nas costas e a sensação de dever cumprido. Temido pela responsabilidade, pelos prazos que sempre estouram, pelas leituras que não cessam de ser exigidas, temido como era o senhor do tempo na mitologia grega, o titã que devorava seus filhos por medo de que estes o destronasse. Mas dia a dia, mês a mês, vai se realizando. Há também o tempo aion, o tempo dos tempos que encontram. Como o guia da carruagem, paira-se diante de três estradas. Talvez sejam a memória, o tempo passado; o sonho, o tempo futuro; e o presente, o tempo que nunca existe. Mas poderia ser também o encontro dos três tempos, entrando em erupção diante de nós. O tempo kairós, pessoalmente o mais especial, é muito fino e difícil de perceber. Mas é o tempo que nos dá a certeza de qual caminho seguir, o tempo que não é conduzido, mas nos conduz. Na mitologia, "Kairós corria rapidamente e só era possível detê-lo agarrando-o pelos cabelos, encarando-o de frente. Porém, depois que ele passava, era impossível trazê- lo de volta. Devido a tal agilidade, Kairós podia não ser percebido pelo observador desatento." (FILGUEIRAS, 2015) Senti-o em alguns momentos, e minhas mudanças do ano de 2016 refletem isso. É um tempo em que tudo muda, ou tudo volta a um ponto original. É palpável e perceptível apenas quando se está nele e parece submeter o chronos e o aion. Sua linha tênue é o ponto chave para se escrever.

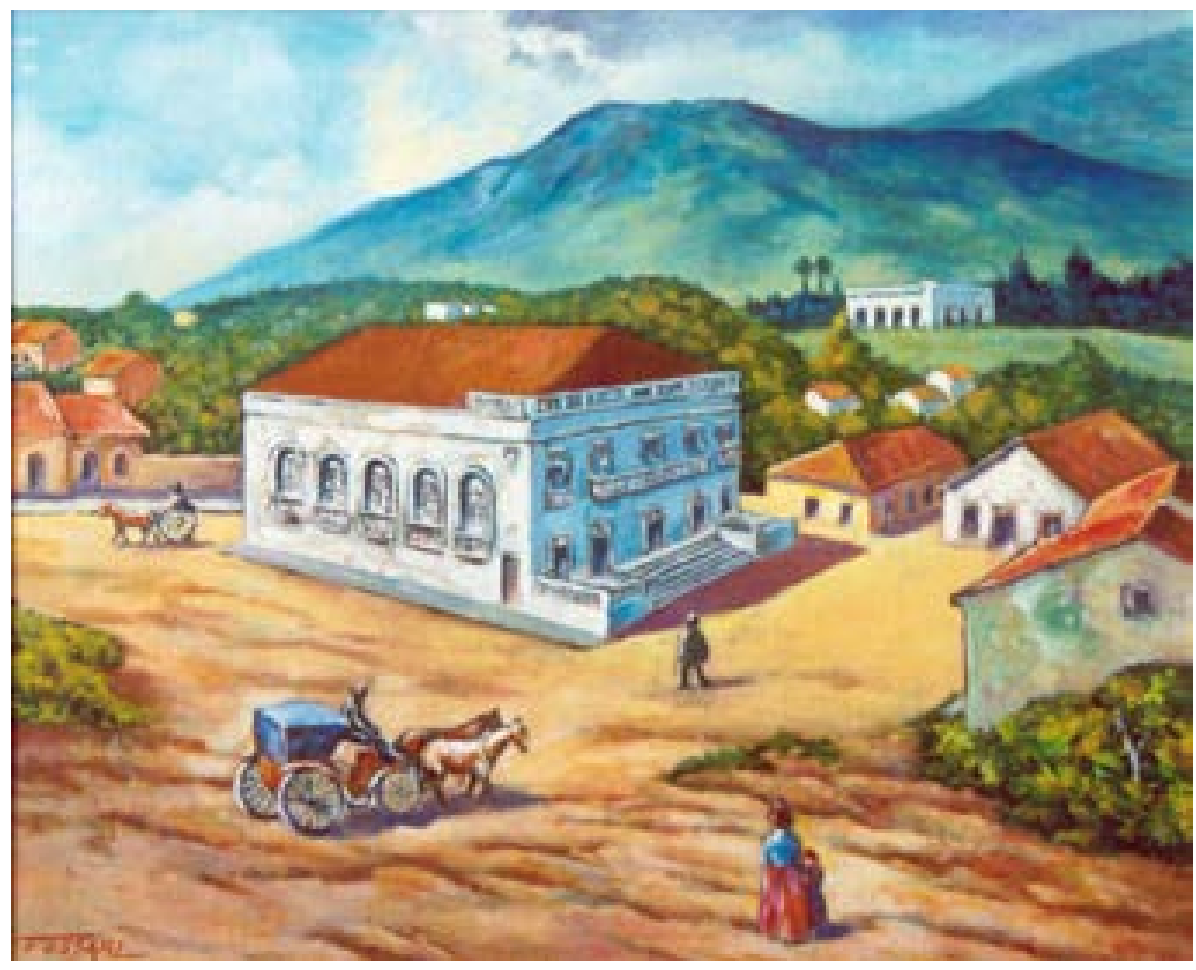

Imagem 8: Fossari, Teatro Álvaro de Carvalho no século XIX. Óleo sobre tela, Acervo Irene Fossari 
Ainda sobre o tempo, vejo o passado na tradição que se atualiza formalmente em Meyer Filho, assim como nossas memórias surgem diante de nós, olhadas agora com outros olhos. Vejo o presente na obra de Pléticos, onde a cidade é forma. $O$ tempo presente não existe, a rapidez da vida moderna me faz passar pela cidade sem olhar. Ao mesmo tempo em que não vejo as formas específicas, vejo-a como uma forma única, homogênea de prédios, linhas, volumes e luzes. E vejo o futuro em Eli Heil: um ovo sendo chocado, alguma coisa que guarda o ainda invisível, cujo produto será um pássaro que voa sem destino. É como o morro que esconde o que se tem à frente e as perguntas que cabem diante das erupções possíveis: elas não estarão intrínsecas na minha escrita?

Na obra de Fabiana Wielewicki (imagem 9), vejo-me contemplando a cidade, estático. É a cidade que vejo em Florianópolis, pela janela do meu carro, a cidade de Paris que vejo pelo quadro em minha sala, pela cidade de Ibirama que vejo da janela do meu apartamento, a cidade de Tubarão que vejo pela janela da minha memória, as cidades do mundo que vejo pelas janelas do meu computador. Como em Marguerite Duras, a solidão que acompanha a escrita não é solidão (1994, p. 17). Estou acompanhado de muitos invisíveis. De muitos que também pairam na janela, olhando o além sem um pensamento específico. Olhando para o além vendo muito além do que os olhos veem.

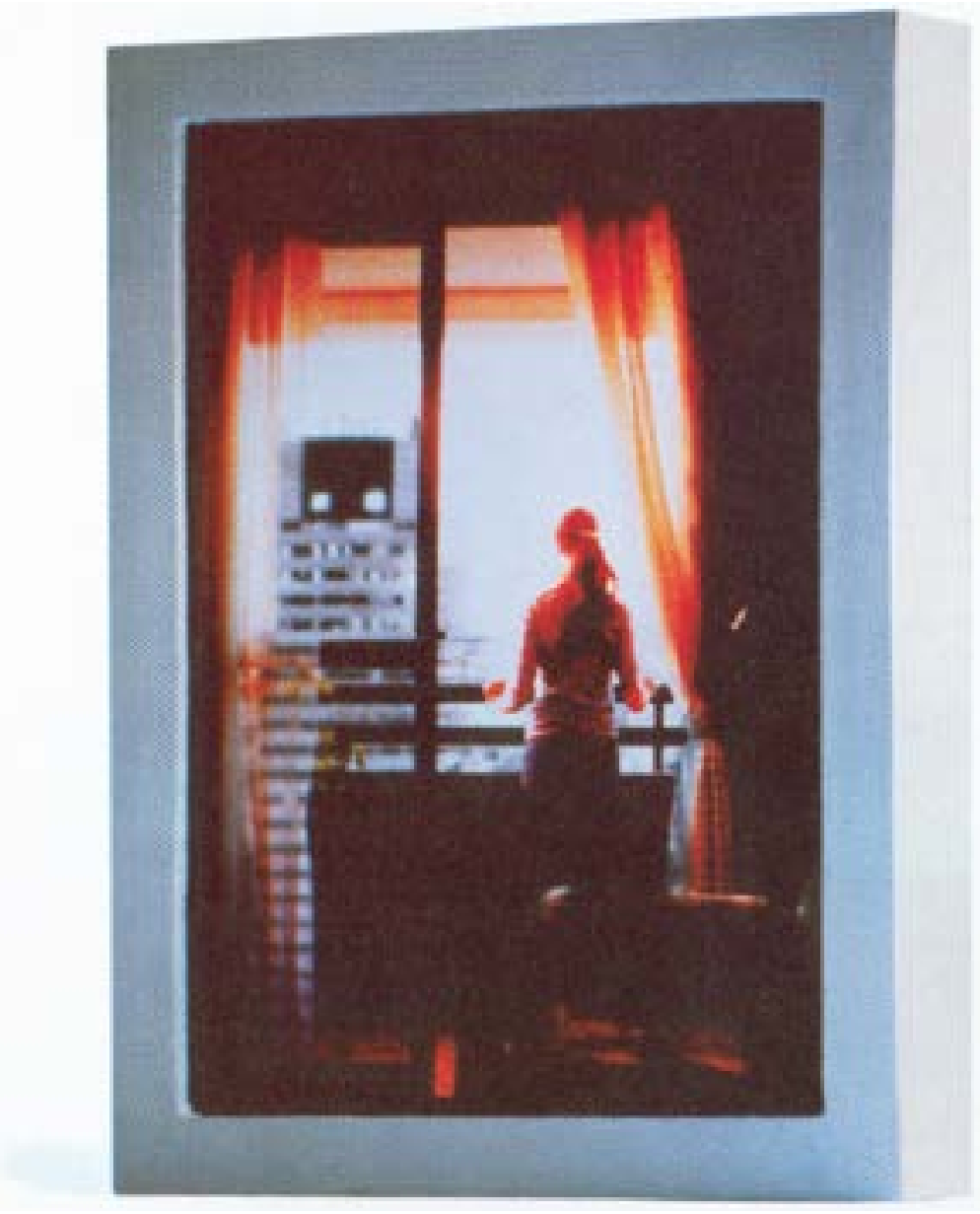

Imagem 9: Fabiana Wielewicki. Série 21 andar autorretrato com paisagem. 2001. Vidro, madeira, impressão sobre acetato. Museu de Arte de Santa Catarina. 
Voltando à tela de Constable: o viajante percorreu uma trajetória e pode retornar ao castelo para tentar preencher as lacunas da ruína. Alves-Mazzotti $(2006$, p. 30) afirma que

É a familiaridade com o estado do conhecimento na área que torna o pesquisador capaz de problematizar um tema, indicando a contribuição que seu estudo pretende trazer à expansão dese conhecimento, quer procurando esclarecer questões controvertidas ou inconsistências, quer preenchendo lacunas.

Talvez satisfaça-o preencher as lacunas de Hadleigh. Talvez não. Novas brechas serão encontradas, ou até outros castelos em ruínas. O caminho será retomado, com novos problemas e novos desafios. Por fim, o caminho para a tese/dissertação é um caminho sem volta e sem fim. Nunca taparemos todas as lacunas, novas perguntas e paisagens surgirão, prontas a serem exploradas. Mas também porque, como afirma Maria Ester de Freitas, "nós somos o maior objeto da tese, pois enquanto sujeito dela vivemos um embate de forças internas e externas que nos ensina muito sobre nós mesmos." Então nós, pesquisadores, assim como viajantes, não teremos casas únicas, só estrada e chão a percorrer, numa viagem de descobertas e autodescobertas, em que, tal como os cães de Constable, a escrita possivelmente não nos abandonará, como não abandonou Marguerrite Duras (1994, p. 15). Boa sorte para todos nós.

\section{Referências}

ALVES-MAZZOTTI, Alda Judith. A "revisão da bibliografia" em teses e dissertações: meus tipos inesquecíveis- o retorno. In: BIANCHETTI, L. MACHADO, A.M.N. (orgs.) A bússola do escrever. Florianópolis: Ed. Cortez \& Ed. da UFSC, 2006.

DURAS, Marguerite. Escrever. Trad. Rubens Figueiredo. São Paulo: Editora Rocco, 1994.

FILGUEIRAS, Amauri V. O Tempo de Salomão. O Eclesiastes e a Sociedade Contemporânea. Uma visão a respeito dos tempos no Cronos, Kairós e Aion. Revista Pandora Brasil, n. 69, dez- 2015. Disponível em: http://revistapandorabrasil.com/revista_pandora/kronos_kairos_69/amauri.pdf Acesso em 26 jun 2016.

FREITAS, Maria Ester de. Viver a tese é preciso! IN: In: BIANCHETTI, L. MACHADO, A.M.N. (orgs.) A bússola do escrever. Florianópolis: Ed. Cortez \& Ed. da UFSC, 2006.

MAKOWIECKY, Sandra. A representação da cidade de Florianópolis na visão dos artistas plásticos. Florianópolis: DIOESC, 2012. 